Article

\title{
Design of an LED Spot Light System with a Projection Distance of $10 \mathrm{~km}$
}

\author{
Chi-Shou Wu ${ }^{1}$, Kuan-Yu Chen ${ }^{1}$, Xuan-Hao Lee ${ }^{1, *}$, Shih-Kang Lin ${ }^{1}$, Ching-Cherng Sun ${ }^{1,2}$, \\ Jhih-You Cai ${ }^{1}$, Tsung-Hsun Yang ${ }^{1}$ and Yeh-Wei Yu ${ }^{1}$ \\ 1 Department of Optics and Photonics, National Central University, Chung-Li 32001, Taiwan; \\ s105286005@dop.ncu.edu.tw (C.-S.W.); s104226037@dop.ncu.edu.tw (K.-Y.C.); \\ s105286002@dop.ncu.edu.tw (S.-K.L.); ccsun@dop.ncu.edu.tw (C.-C.S.); \\ s992406002@dop.ncu.edu.tw (J.-Y.C.); thyang@dop.ncu.edu.tw (T.-H.Y.); ywyu@dop.ncu.edu.tw (Y.-W.Y.) \\ 2 Department of Electrophysics, National Chiao Tung University, Hsin-Chu 30010, Taiwan \\ * Correspondence: xuanhao.lee@gmail.com or s9424006@dop.ncu.edu.tw; Tel.: +886-3-422-7151
}

Received: 9 September 2019; Accepted: 12 October 2019; Published: 13 October 2019

check for updates

\begin{abstract}
We designed a spot light system with an illumination range of $10 \mathrm{~km}$. In the designed system, an appropriate white light-emitting diode (LED) was selected according to the exitance and injection power required. Subsequently, through a first-order optical design, the geometry of the lens and reflector was determined using geometrical calculation. Because the central illuminance of the projection spot of the reflector was 2.5 times that of the cover lens, we first considered the fabrication error of the reflector. According to the adjustment of the optimized distance between the white LED and reflector, we modified the design of the cover lens to fit the new location of the white LED. An LED spot light module containing 16 spot light units was used. The module's power injection was only $68.2 \mathrm{~W}$. Because of the excellent performance of the designed system in terms of the divergence angle of the projection beam and maximum luminous intensity, which were $1.6^{\circ}$ and 2,840,000 cd, respectively, the projection distance of the LED spot light module was $3.37 \mathrm{Km}$, according to the ANSI regulation. Finally, a spot light system with nine modules and capable of achieving a projection distance of $10 \mathrm{~km}$ was successfully fabricated.
\end{abstract}

Keywords: white LED; long-distance projection; exitance; spot light

\section{Introduction}

White light-emitting diodes (LEDs) have been extensively applied in general lighting and special lighting [1-5], such as stadium [6], museum [7], and workplace lighting [8], thanks to their superior characteristics, including long life, compact size, vivid color, fast response, and environmental benefits [9-16]. A white LED is mostly fabricated by covering a blue die with yellow phosphor; such a white LED is also called a phosphor-converted white LED (pcW-LED) [17]. The die refers to the LED chip, which is the core device of LED illumination. Yellow phosphor can transform blue light into yellow light and balance the leakage blue light to provide white light. Therefore, achieving a stable transformation from blue light to yellow light and fixing the color coordinate of the targeted white light are important tasks. However, fixing the color coordinate is difficult because the heat generated by the blue die is transferred to the phosphor layer and thus causes thermal quenching, which reduces the quantum efficiency of the phosphor layer and changes the color coordinate and color temperature [18]. Therefore, the thermal problem is critical in LED lighting, especially when the driving power is large.

Traditional plasma-type light sources are applied in projection lamps, including automotive headlamps and long-distance projection lamps, due to their large exitance [19-29]. By contrast, the exitance of a pcW-LED is limited because the power density of a pcW-LED is strictly limited. 
Although higher power density can be achieved under a special design for heat dissipation, the system cost increases. In this study, we measured the exitance and injection current density of six types of commercial pcW-LEDs. The aforementioned measurements were conducted using a thermoelectric cooler to control the board temperature at $100^{\circ} \mathrm{C}$; moreover, the flux was measured using pulse driving current. We found that compared with the other pcW-LEDs, Osram HWQP had a larger exitance and higher current injection density at a power density of $5 \mathrm{~W} / \mathrm{mm}^{2}$ [30]. Thus, Osram HWQP was determined to be more suitable than the other pcW-LEDs for designing a compact long-distance spot light system. This paper presents the design details of the spot light system and results obtained through an experimental evaluation of the system. We used the ANSI regulation to calculate the beam distance, defined as the distance from the luminaire at which the measured illuminance is equivalent to 0.25 lux [31]. Finally, we evaluated the final version of the LED projection system and verified that the projection distance could reach $10 \mathrm{~km}$.

\section{Optical Modeling}

Due to its superior exitance and power density, Osram HWQP was selected as the light source of the 10-km projection lamp. The pcW-LED of Osram HWQP is displayed in Figure 1, in which the yellow region is the active emitting area. The lateral dimensions of the pcW-LED of Osram HWQP were measured to be $1 \mathrm{~mm} \times 1 \mathrm{~mm}$. To achieve a $10 \mathrm{~km}$ projection distance, the divergence angle of the lamp must be extremely small, and the optical model should be sufficiently precise. To build a precise light source model, we must obtain accurate light source dimensions. There exists an empty area at the upper corner. The datasheet of Osram HWQP indicates that its angular full width at half maximum (FWHM) is $120^{\circ}$ [30], which coincides with the feature of a Lambertian light source. This property can thus facilitate the modeling process. The yellow part in Figure 1 represents the Lambertian emitting area. To ensure the accuracy of the light source model for practical application, we must measure the light patterns in the midfield regime [32-34]. Figure 2 displays the simulation algorithm and the corresponding experimental setup; in the measurement, the pcW-LED was located at the center of the rotational axis of the rotational stage. By controlling the iris size, we could control the angular resolution in the measurement. Figure 3 illustrates a comparison of the simulation and the measurement results in the midfield regime. Nearly all normalized cross-correlation (NCC) values were higher than $99.9 \%$ in both the horizontal and vertical directions [35]. This indicates that the Osram HWQP optical model is sufficiently precise in our design.

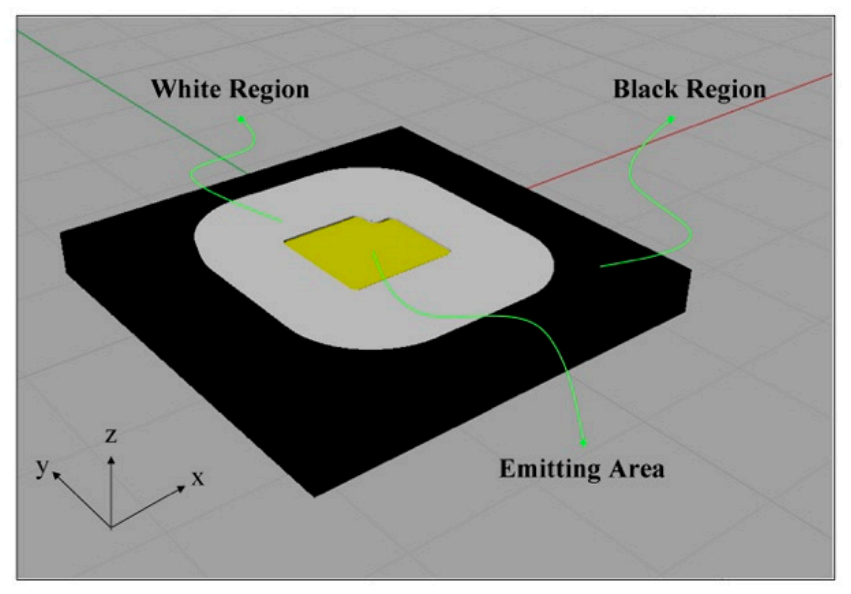

Figure 1. Geometry of Osram HWQP LED. 

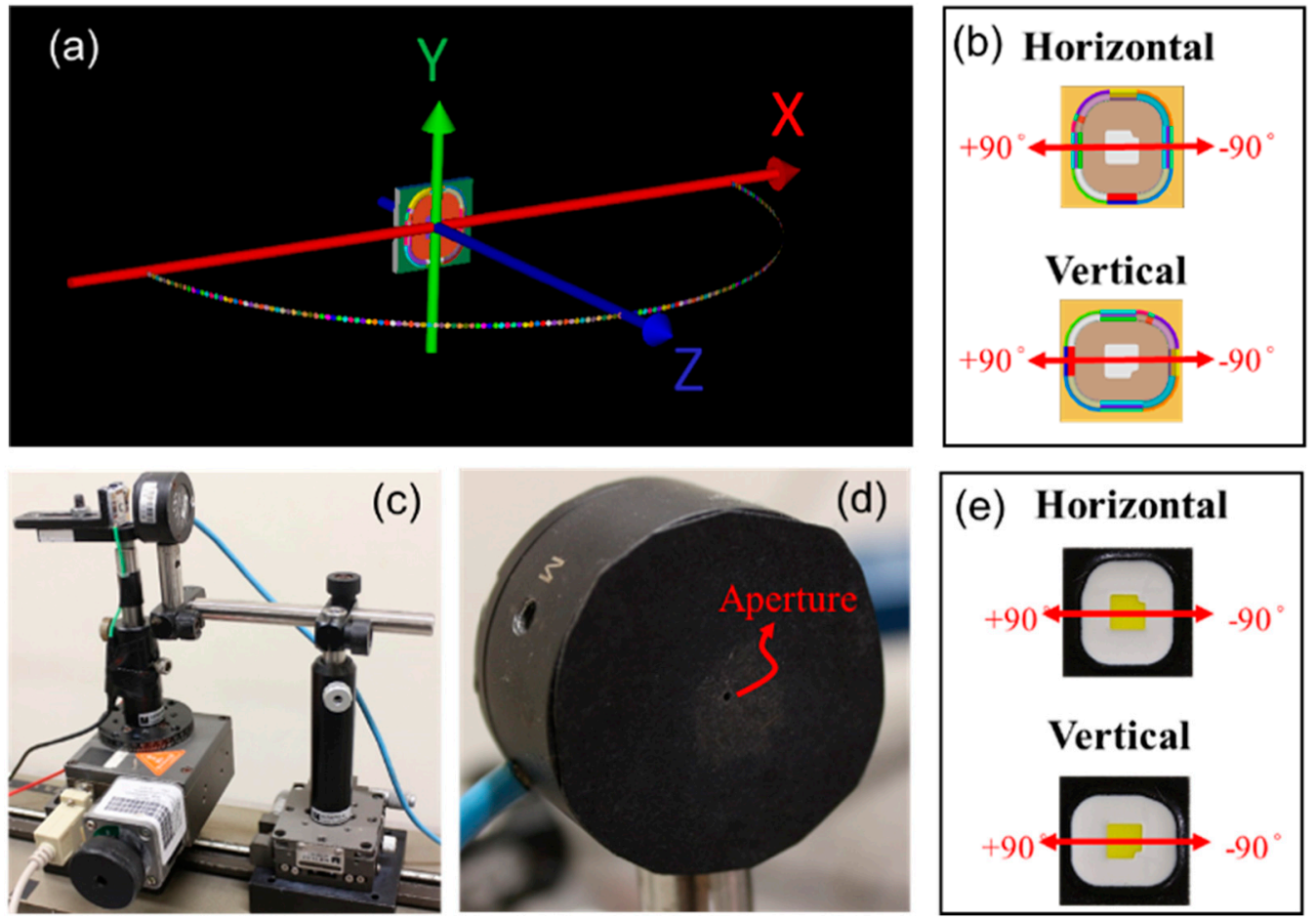

Figure 2. (a) Algorithm used in the simulation along the (b) horizontal and vertical directions. (c) Optical setup in the experimental measurement, with a controllable iris shown in (d), along the (e) horizontal and the vertical directions.
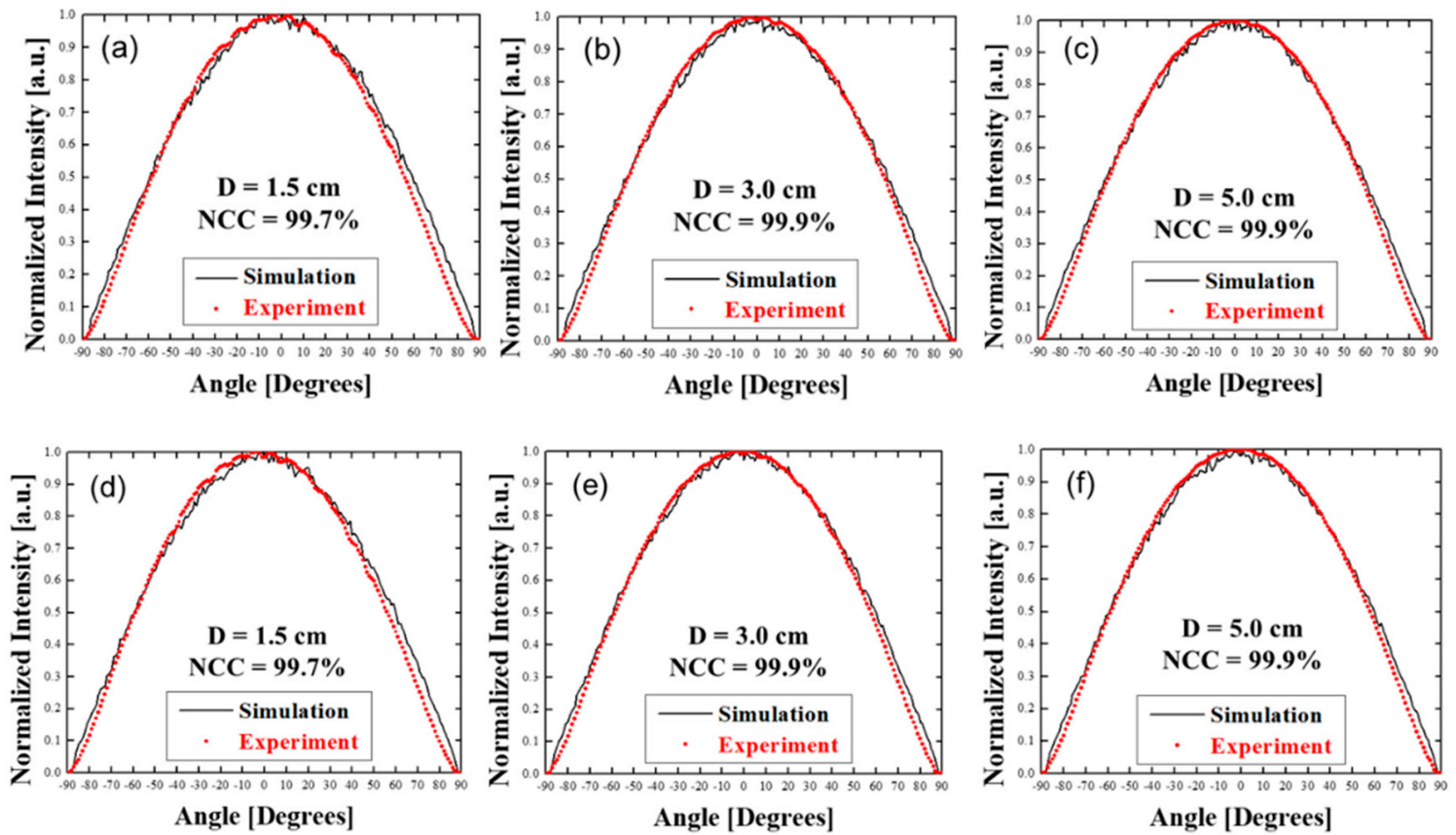

Figure 3. Comparison of the simulated and measured normalized cross-correlation values in the midfield regime and beyond along the horizontal direction at the distance of (a) 1.5 , (b) 3, and (c) $5 \mathrm{~cm}$ and along the vertical direction at the distance of (d) 1.5 , (e) 3 , and (f) $5 \mathrm{~cm}$.

\section{Optical Design and Optimization}

The first-order optical design objective was to determine a rough geometry for achieving a projection spot with a sufficiently narrow divergence angle. In addition, we endeavored to collect all the flux to increase the illuminance on the target at a distance of $10 \mathrm{~km}$. An appropriate approach 
to this goal would be to use a TIR lens for collecting the light emitted along all directions [36-39]. However, a volume-limited TIR lens would be unsuitable for achieving a high flux and an extremely small divergence angle; instead, a hybrid system comprising a lens with a parabolic reflector would be more suitable. According to the ANSI regulation, the farthest distance is the maximum distance at which the illuminance is at least 0.25 lux [31]. To reach this target, we used LED clusters to emit a sufficiently high flux. Our data indicated that the pcW-LED could be driven at a maximum power of $5.2 \mathrm{~W}$, where the current injection was determined to be $1.5 \mathrm{~A}$. The objective of the proposed design was not to drive the power to this level. In the experimental measurement, the pcW-LED emitted a stable flux of $340 \mathrm{~lm}$ under a designed heat dissipation structure with a power injection of approximately 4.3 $\mathrm{W}$. Therefore, the pcW-LED was driven at this power when the entire system was assembled. Our aim was to maintain the total power of the pcW-LEDs below $700 \mathrm{~W}$. Therefore, we used $144 \mathrm{pcW}$-LEDs. In the first step of calculation, we obtained a total flux of $48960 \mathrm{~lm}$ and targeted illuminance of 0.25 lux. Projecting the entire portion of light onto a target is impractical. In our experience, $40-50 \%$ of light may be projected to the target area. This thus signifies that the optical utilization factor (OUF) is $40-50 \%$. To simplify the calculation, if the target illumination area is $\mathrm{t}^{2}, \mathrm{t}$ would be $313 \mathrm{~m}$. The expected projection distance reaches $10 \mathrm{~km}$. Therefore, the full divergence angle of the spot light was determined to be $1.79^{\circ}$. Regarding the effective area $\left(1 \mathrm{~mm}^{2}\right)$ of the $\mathrm{pcW}$-LED, the projection lens should be located at a distance of $33.8 \mathrm{~mm}$ from the top surface of the pcW-LED. We could then determine the vertical dimension of the optical system. To determine the diameter of the reflector, we set the divergence angle to $1.79^{\circ}$ and the reflector length $(L)$ to $33.8 \mathrm{~mm}$. As displayed in Figure 4 , a parabolic reflector was used to collimate the light at larger angles. The nonzero divergence angle was caused by the lateral extension of the emitting area of the pcW-LED. When the length of the reflector was $33.8 \mathrm{~mm}$, the light primarily contributing to the divergence angle originated from the reflector nearly halfway through the length of the reflector (i.e., $16.9 \mathrm{~mm}$ ), as depicted in Figure $5 \mathrm{a}$. If the radius of the open top of the reflector is $r$, the lateral extension of the light source can be $\Delta \mathrm{r}$ and the half divergence angle $(\Delta \theta)$ can be expressed as follows:

$$
\Delta \theta=\tan ^{-1}\left(\frac{r+\Delta r}{L}\right)-\tan ^{-1}\left(\frac{t}{L}\right)
$$

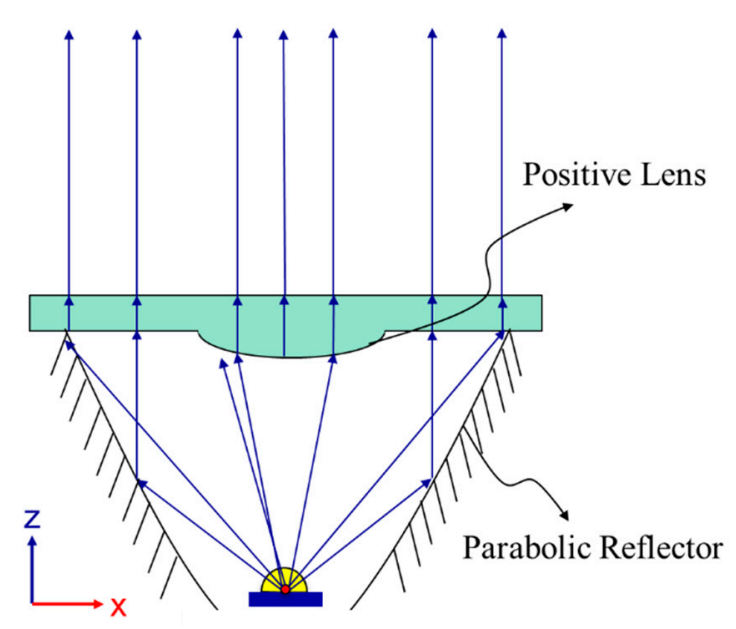

Figure 4. Basic optical structure of the projection light. 


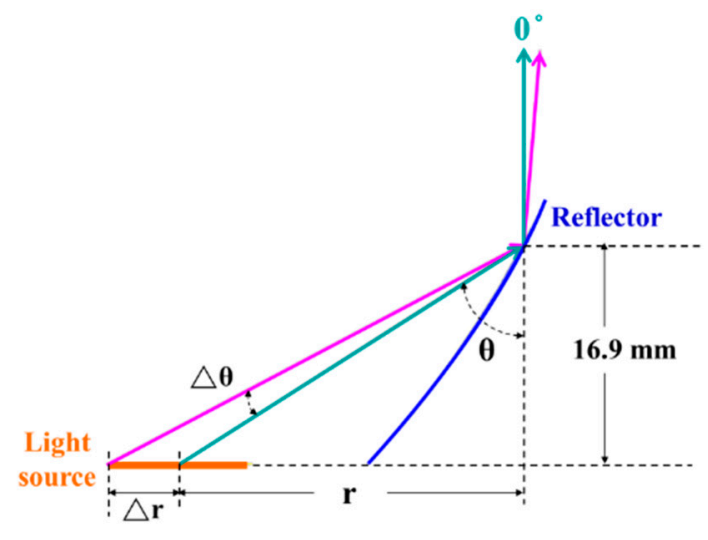

(a)

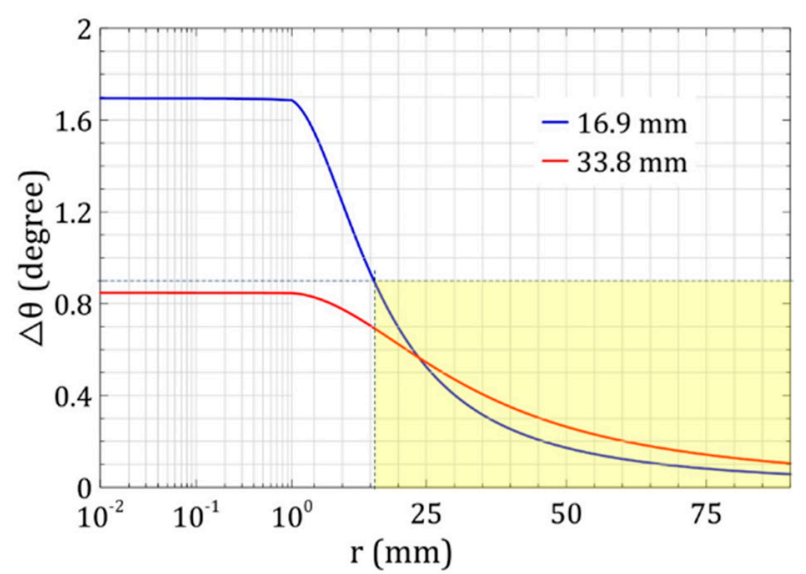

(b)

Figure 5. (a) Schematic of the reflector when controlling the divergence angle and (b) plot of the half divergence angle versus the radius of the reflector.

Figure $5 \mathrm{~b}$ illustrates a plot of $\Delta \theta$ versus $r$ at $\mathrm{L}$ values of 33.8 and $16.9 \mathrm{~mm}$. To achieve a divergence angle smaller than $1.79^{\circ}$, the radius of the parabolic reflector should be larger than $16 \mathrm{~mm}$. However, Figure 4 illustrates that the cover lens occupies the central area of the projection system. Therefore, the reflector surface should be moved outward. Consequently, the diameter of the lens would also be limited. The diameter of the lens was set $32 \mathrm{~mm}$, and the diameter of the open top of the reflector was set to $65 \mathrm{~mm}$.

Figure 6 presents the layout of the optical components, including the parabolic reflector and cover lens. The figure reveals that the emitting area of the pcW-LED is located at the focus of the parabolic reflector. The cover lens is placed on the open top of the reflector, and the lens is attached to the center of the cover. Because of the 32-mm diameter of the lens, a clear ring aperture can be obtained for the light reflected by the parabolic reflector. Our simulation revealed the central illuminance levels (full divergence angles) to be approximately $2515 \operatorname{lux}\left(1.38^{\circ}\right), 1034$ lux $\left(1.2^{\circ}\right)$, and 3549 lux $\left(1.33^{\circ}\right)$ for the parabolic reflector, cover lens, and entire system, respectively. Accordingly, the projection spot of the entire system fits the first-order design objective.

In practice, a reflector and cover lens incur a certain amount of distortion during mass production, in which optical components are formed using the plastic medium and an injection molding machine. One drawback is that the shrinkage or distortion rates of the reflector and lens may be different, which could cause defocusing of the optical components. To avoid this situation, a component must be fabricated first, after which other components are adjusted by considering the distortion of the fabricated component. The central illuminance of the projection spot of the reflector was determined to be approximately 2.5 times that of the cover lens. Moreover, controlling reflector distortion would be more difficult than controlling cover lens distortion because of the larger size and complicated shape of the reflector. Therefore, we decided to fabricate the reflector first. The reflector was fabricated using an injection molding machine and coated with aluminum. To ensure a suitable fabrication tolerance, we examined the defocus level by adjusting the longitudinal distance of the pcW-LED attached to an MCPCB (Figure 7). In the original design, the emitting surface of the pcW-LED was located at $+0.5 \mathrm{~mm}$ from the bottom of the reflector; however, in the experiment, the best position was found to be approximately $-0.1 \mathrm{~mm}$ from the bottom of the reflector (Figure $8 \mathrm{a}$ ). Figure $8 \mathrm{~b}$ illustrates the illuminance at a distance of $10 \mathrm{~m}$ for nine reflectors. Although the best positions were different for nine reflectors, the position at $-0.1 \mathrm{~mm}$ was the optimal one. Thus, the distortion of the reflector caused a defocus of $0.6 \mathrm{~mm}$. The measured central illuminance varied from 2403 to 2569 lux, representing $96-102 \%$ of the simulation value. 
(a)

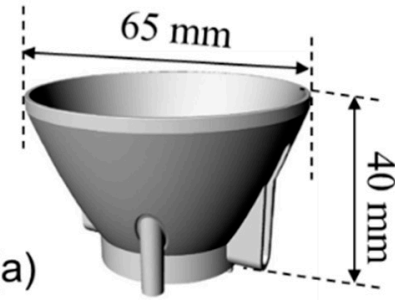

Reflector

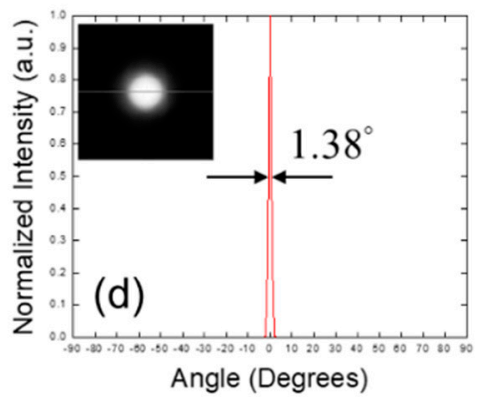

(b)

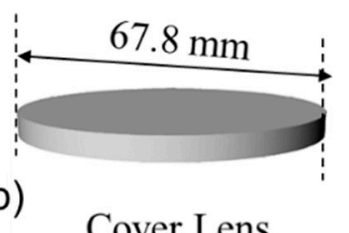

Cover Lens

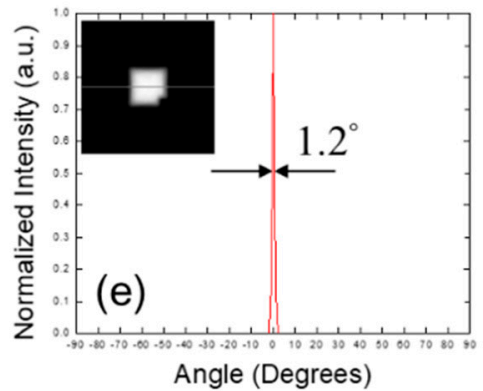

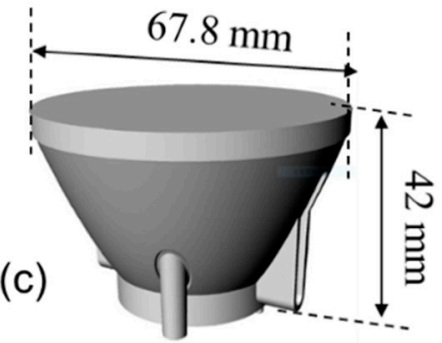

Reflector + Cover Lens

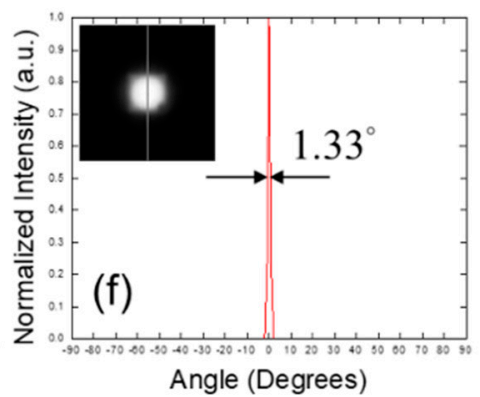

Figure 6. Structure of the (a) parabolic reflector, (b) cover lens, and (c) entire system. Simulated projection spot at a distance of $1 \mathrm{~km}$ and divergence angle of the light coming from the (d) parabolic reflector, (e) cover lens, and (f) entire system.

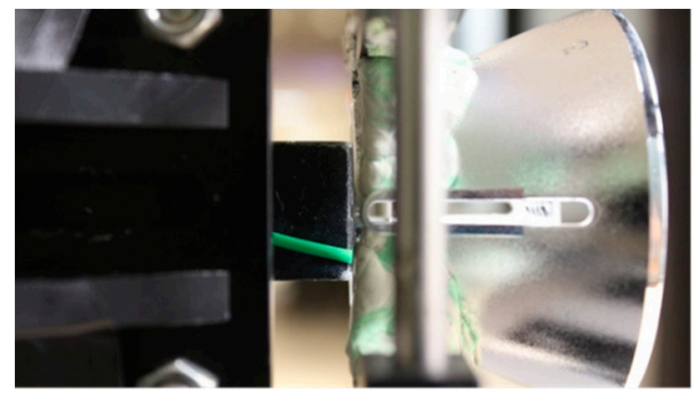

(a)

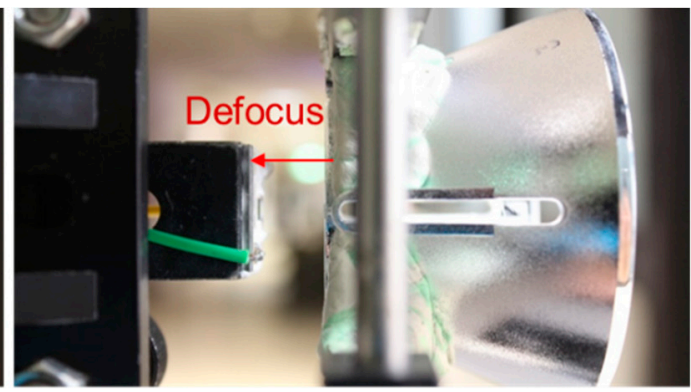

(b)

Figure 7. Distance between the pcW-LED and reflector was adjusted when (a) the pcW-LED was at the designed position and (b) departed from the position in (a).

We adjusted the location of the pcW-LED to the optimized position by considering the fabricated reflector. We then modified the lens shape to shorten the focal length. The lens diameter was adjusted to $31.84 \mathrm{~mm}$ to fit the optimized position of the pcW-LED (Figure 9). The central illuminance (divergence angle) varied from $1035 \operatorname{lux}\left(1.2^{\circ}\right)$ to 1032 lux $\left(1.19^{\circ}\right)$ in the simulation. The cover lens was made with PMMA using the injection molding machine. Figure 10 displays the projection spots for the nine samples. The measured central illuminance ranged from 791 to 915 lux, representing $77 \%$ to $89 \%$ of the simulation value. The degradation of illuminance may have been caused by the deformation of the lens during its manufacturing, where defocus, distortion, and dispersion may have been induced. Finally, the measured central illuminance of the spot light unit was 2895-3298 lux, representing 86-98\% of the simulation value (Figure 11). 


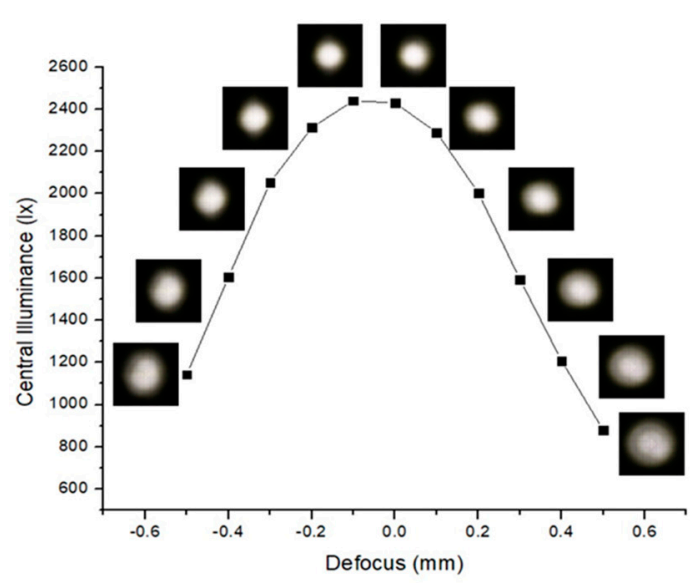

(a)

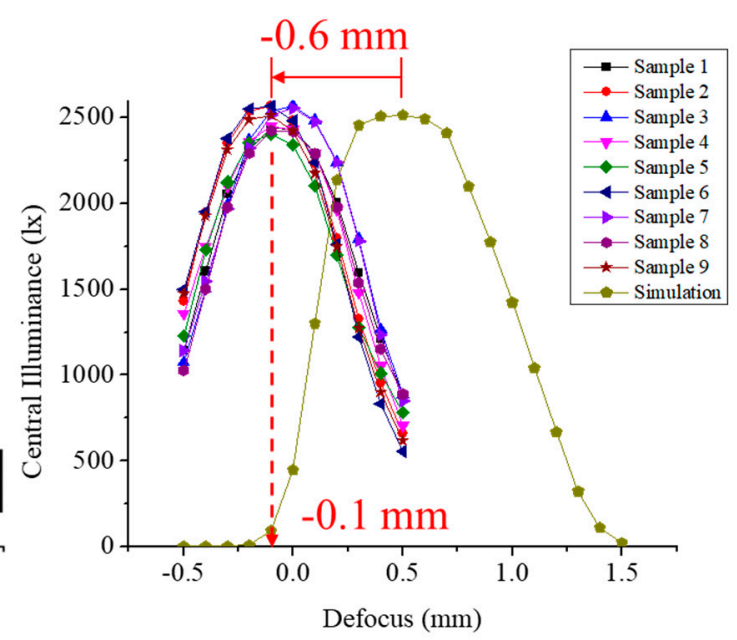

(b)

Figure 8. (a) Projection spots and variation of the central illuminance when the pcW-LED was shifted longitudinally. (b) Plot of the measured central illuminance versus the defocus for nine samples. The dark green line represents the results for the original design. The measurement was conducted for an injection current of $1.5 \mathrm{~A}$ with a heavy heat sink.

(a)

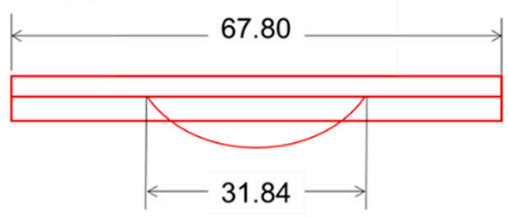

(b)

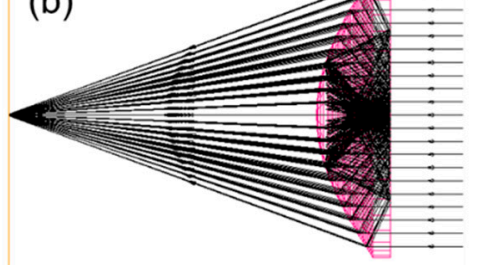

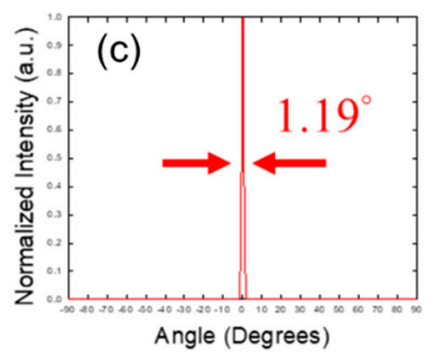

Figure 9. (a) Structure of the modified cover lens; (b) ray fans in the simulation; and (c) divergence angle of the spot light.

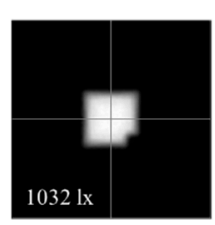

(a)

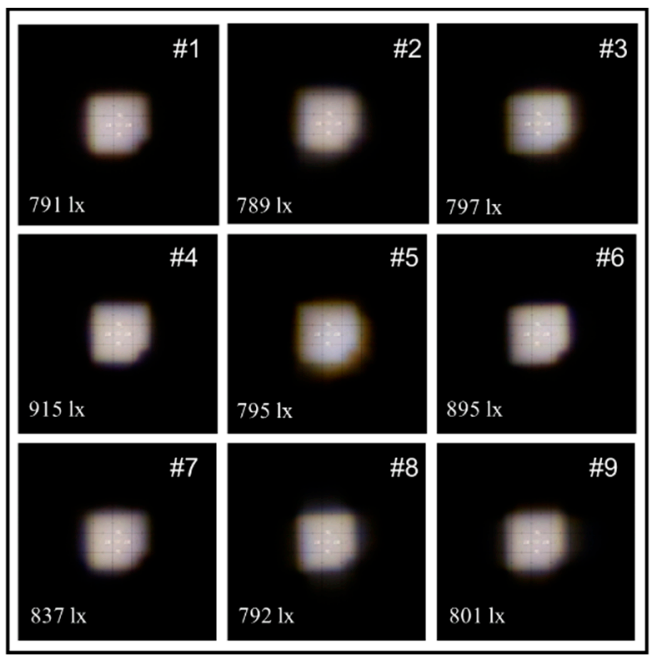

Figure 10. (a) Simulated projection spot of the cover lens at a distance of $10 \mathrm{~m}$ and (b) corresponding measurement for the nine samples. The measurements were conducted at an injection current of $1.5 \mathrm{~A}$ with a heavy heat sink. 


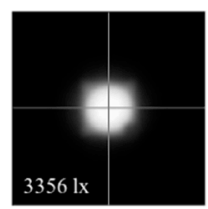

(a)

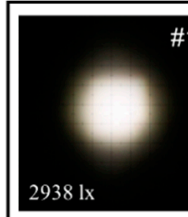

(b)
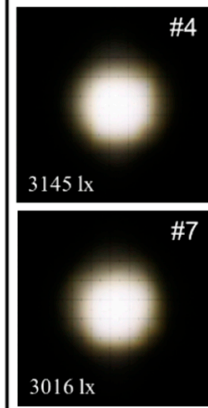

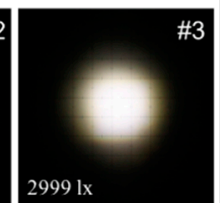

\#5
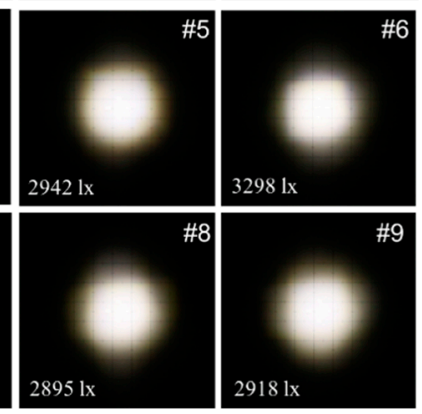

Figure 11. (a) Simulated projection spot of the spot light unit at a distance of $10 \mathrm{~m}$ and (b) corresponding measurements for the nine samples. The measurements were conducted at an injection current of $1.5 \mathrm{~A}$ with a heavy heat sink.

\section{Performance of the Spot Light System}

To achieve a projection distance of $10 \mathrm{~km}$, we constructed a spot light module comprising 16 spot light units. The final system contained nine modules; thus, the entire system contained 144 spot light units. Figure 12 displays one of the modules; the total power, injection current, divergence angle, and maximum luminous intensity of the module were $68.2 \mathrm{~W}, 1.25 \mathrm{~A}, 1.6^{\circ}$, and 2,840,000 cd, respectively. The projection distance was $3.37 \mathrm{~km}$, according to the ANSI regulation [31]. Figure 13 illustrates the entire system. The projected light split at a short distance and then merged toward a round spot at a farther distance [40]. Finally, the entire system projected light to a distance of $10 \mathrm{~km}$ at steady state. The total electric power of the entire system was less than $700 \mathrm{~W}$. Compared with traditional xenon projection lamps, whose electric power is in kilowatts, the proposed system exhibited greater energy-saving effects. Heat considerably affects LEDs, and the power density of an LED is limited. Therefore, an adequate heat dissipation design is required. Moreover, due to the high luminous intensity of the proposed system, attention should be paid to photobiological safety to prevent strong light from causing damage to the human eye [41,42].
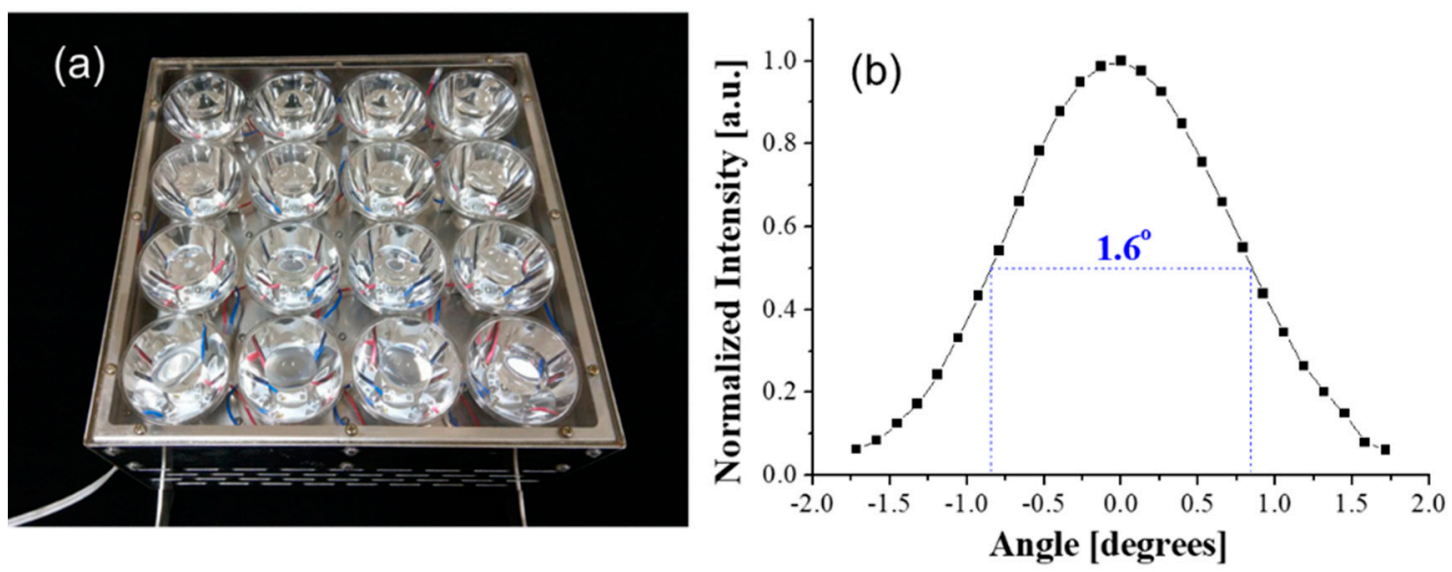

Figure 12. (a) Spot light module and (b) measured intensity distribution. 

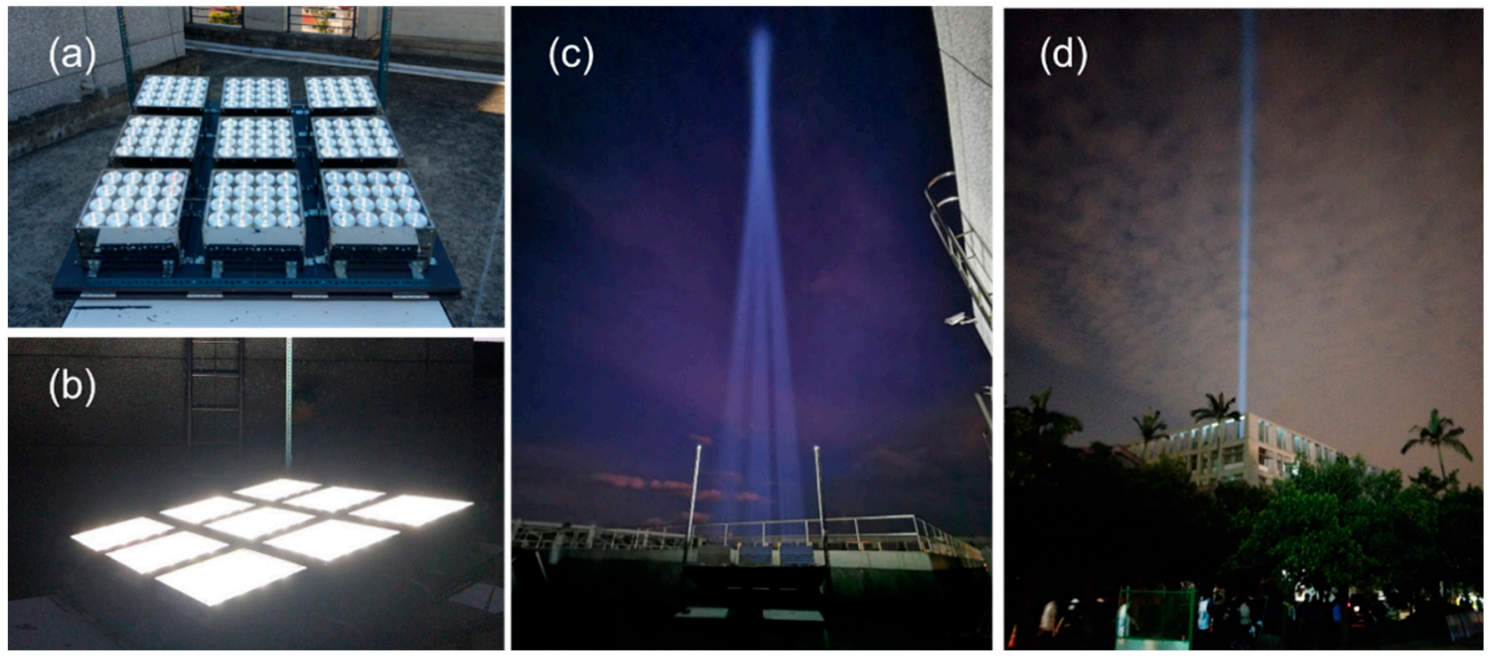

Figure 13. (a,b) Entire spot light system for 10-km projection; (c) light paths from the system; and (d) light path observed at a distance far away the system.

The proposed system is suitable for several applications due to its advantages such as compact size and low energy consumption. It is suitable for use in ships and fishing boats. Large-volume multicombination projection systems are suitable for use in lighthouse and bird towers.

\section{Conclusions}

In this study, we designed a white LED spot light system to achieve a 10-km projection distance. We created the design after comparing six commercial high-power white LEDs on the basis of their exitance and injection power. Subsequently, we selected Osram HWQP as the light source. Through precise optical modeling of the light source, we decided to use a hybrid optical system containing a cover lens and parabolic reflector rather than a TIR lens. The expected projection distance was $10 \mathrm{~km}$. Therefore, the full divergence angle of the spot light system was $1.79^{\circ}$. Regarding the effective area $\left(1 \mathrm{~mm}^{2}\right)$ of Osram HWQP, the projection lens should be located at a distance of more than $33.8 \mathrm{~mm}$ from the top surface of the pcW-LED. The minimum radius of the reflector was determined through simple geometrical calculation.

Considering practical fabrication errors, we fabricated the reflector first through an injection molding machine. The reflector's distortion changed the best location of the pcW-LED from +0.5 to -0.1 $\mathrm{mm}$ on a reference plane. The cover lens was then modified to fit the new location. The measured central illuminance of the reflector was 2403-2569 lux, representing 96-102\% of the simulation value, and that of the cover lens was 791-915 lux, representing 77-89\% of the simulation value. The degradation of illuminance was possibly due to the deformation of the lens during manufacturing, where defocus, distortion, and dispersion may have been induced. Finally, the measured central illuminance of the spot light unit was $2895-3298$ lux, representing $86-98 \%$ of the simulation value.

The entire system contained nine modules, each of which comprised 16 LED spot light units. The power injection of each module was only $68.2 \mathrm{~W}$. Because of the excellent performance of the LED spot light module in terms of the divergence angle of the projection beam and maximum luminous intensity, which were $1.6^{\circ}$ and 2,840,000 cd, respectively, the projection distance of the module could reach $3.37 \mathrm{~km}$, according to the ANSI regulation [31]. Finally, the projection distance of the entire system was demonstrated to reach approximately $10 \mathrm{~km}$ with a divergence angle of $1.6^{\circ}$. 
Author Contributions: Conceptualization and writing work, C.-C.S.; Simulation, K.-Y.C.; Experiment, C.-S.W., X.-H.L., K.-Y.C., S.-K.L., and J.-Y.C.; part of calculation, T.-H.Y., C.-C.S., C.-S.W., X.-H.L.; discussion, Y.-W.Y.

Funding: This research has been funded by the Ministry of Science and Technology of the Republic of China, grant numbers MOST 106-2221-E-008-065-MY3 and 108-2622-E-008-010-CC2.

Acknowledgments: The author would like to thank BRO for sponsoring ASAP, Benex for supporting in fabrication of the optical components, and all team members led by Ching-Cherng Sun and Tsung-Hsun Yang for assembling the whole system.

Conflicts of Interest: The authors declare no conflict of interest.

\section{References}

1. Wang, S.; Wang, K.; Chen, F.; Liu, S. Design of primary optics for LED chip array in road lighting application. Opt. Express 2011, 19, A716-A724. [CrossRef]

2. Lee, X.H.; Moreno, I.; Sun, C.C. High-performance LED street lighting using microlens arrays. Opt. Express 2013, 21, 10612-10621. [CrossRef] [PubMed]

3. Lee, X.H.; Chang, Y.Y.; Sun, C.C. Highly energy-efficient agricultural lighting by B+R LEDs with beam shaping using micro-lens diffuser. Opt. Commun. 2013, 291, 7-114. [CrossRef]

4. Jafrancesco, D.; Mercatelli, L.; Sansoni, P.; Fontani, D.; Sani, E.; Coraggia, S.; Meucci, M.; Francini, F. Optical design of a light-emitting diode lamp for a maritime lighthouse. Appl. Opt. 2015, 54, 3252-3262. [CrossRef]

5. Lee, X.H.; Yang, J.T.; Chang, J.H.; Chien, W.T.; Lo, Y.C.; Lin, C.C.; Sun, C.C. An LED-based luminaire for badminton court illumination. Lighting Res. Technol. 2017, 49, 396-406. [CrossRef]

6. Fantozzi, F.; Leccese, F.; Salvadori, G.; Rocca, M.; Garofalo, M. LED lighting for indoor sports facilities: Can its use be considered as sustainable solution from a techno-economic standpoint? Sustainability 2016, 8, 618. [CrossRef]

7. Piccablotto, G.; Aghemo, C.; Pellegrino, A.; Iacomussi, P.; Radis, M. Study on conservation aspects using LED technology for museum lighting. Energy Procedia 2015, 78, 1347-1352. [CrossRef]

8. Kim, A.; Wang, S.; McCunn, L.J. Building value proposition for interactive lighting systems in the workplace: Combining energy and occupant perspectives. J. Build. Eng. 2019, 24, 100752. [CrossRef]

9. Narendran, N.; Maliyagoda, N.; Bierman, A.; Pysar, R.; Overington, M. Characterizing white LEDs for general illumination applications. Proc. SPIE 2000, 3938, 240-248. [CrossRef]

10. Steigerwald, D.A.; Bhat, J.C.; Collins, D.; Fletcher, R.M.; Holcomb, M.O.; Ludowise, M.J.; Martin, P.S.; Rudaz, S.L. Illumination with solid state lighting technology. IEEE J. Sel. Top. Quantum Electron. 2002, 8, 310-320. [CrossRef]

11. Zukauskas, A.; Shur, M.S.; Caska, R. Introduction to Solid-State Lighting; John Wiley \& Sons: New York, NY, USA, 2002; ISBN 978-0-471-21574-5.

12. Schubert, E.F.; Kim, J.K. Solid-state light sources getting smart. Science 2005, 308, 1274-1278. [CrossRef] [PubMed]

13. Schubert, E.F. Light-Emitting Diods, 2nd ed.; Cambridge University Press: New York, NY, USA, 2006; ISBN 9780521865388.

14. Krames, M.R.; Shchekin, O.B.; Mueller-Mach, R.; Mueller, G.O.; Zhou, L.; Harbers, G.; Craford, M.G. Status and future of high-power light-emitting diodes for solid-state lighting. J. Disp. Technol. 2007, 3, 160-175. [CrossRef]

15. Pimputkar, S.; Speck, J.S.; DenBaars, S.P.; Nakamura, S. Prospects for LED lighting. Nat. Photonics 2009, 3, 180-182. [CrossRef]

16. Karlicek, B.; Sun, C.C.; Zissis, G.; Ma, R. Handbook of Advanced Lighting Technology; Springer: Cham, Switzerland, 2017; ISBN 978-3-319-00175-3.

17. Sun, C.C.; Chang, Y.Y.; Yang, T.H.; Chung, T.Y.; Chen, C.C.; Lee, T.X.; Li, D.R.; Lu, C.Y.; Ting, Z.Y.; Glorieux, B.; et al. Packaging efficiency in phosphor-converted white LEDs and its impact to the limit of luminous efficacy. J. Soild State Lighting 2014, 1, 19. [CrossRef] 
18. Yang, T.H.; Wu, S.M.; Sun, C.C.; Glorieux, B.; Chen, C.Y.; Chang, Y.Y.; Lee, X.H.; Yu, Y.W.; Chung, T.Y.; Lai, K.Y. Stabilizing CCT in pcW-LEDs by self-compensation between excitation efficiency and conversion efficiency of phosphors. Opt. Express 2017, 25, 29287-29295. [CrossRef]

19. Derlofske, J.F.V.; McClogan, M.W. White LED sources for vehicle forward lighting. Proc. SPIE 2002, 4776, 195-205. [CrossRef]

20. Albou, P. LED modules for front lighting applications. In Proceedings of the 5th International Symposium on Progress in Automobile Lighting, München, Germany, 23-24 September 2003; Herbert Utz Verlag: München, Germany, 2003; Volume 10, pp. 37-51.

21. Luce, T. Customized LED light sources for automotive applications. In Proceedings of the 5th International Symposium on Progress in Automobile Lighting, München, Germany, 23-24 September 2003; Herbert Utz Verlag: München, Germany, 2003; Volume 10, pp. 614-620.

22. Moeller, N. Design aspects and headlamp performance-The left and right headlamp are not the same. In Proceedings of the 5th International Symposium on Progress in Automobile Lighting, München, Germany, 23-24 September 2003; Herbert Utz Verlag: München, Germany, 2003; Volume 10, pp. 686-697.

23. Tatsukawa, M.; Ishida, H.; Sazuka, K. Vehicle Headlamp. U.S. Patent 6,891,333 B2, 10 May 2005.

24. Cvetkovic, A.; Dross, O.; Chaves, J.; Benítez, P.; Miñano, J.C.; Mohedano, R. Etendue-preserving mixing and projection optics for high-luminance LEDs, applied to automotive headlamps. Opt. Express 2006, 14, 13014-13020. [CrossRef]

25. Chen, F.; Wang, K.; Qin, Z.; Wu, D.; Luo, X.; Liu, S. Design method of high-efficient LED headlamp lens. Opt. Express 2010, 18, 20926-20938. [CrossRef]

26. Brick, P.; Schmid, T. Automotive headlamp concepts with low-beam and high-beam out of a single LED. Proc. SPIE 2011, 8170, 817008. [CrossRef]

27. Hsieh, C.C.; Li, Y.H.; Hung, C.C. Modular design of the LED vehicle projector headlamp system. Appl. Opt. 2013, 52, 5221-5229. [CrossRef]

28. Sun, W.S.; Tien, C.L.; Lo, W.C.; Chu, P.Y. Optical design of an LED motorcycle headlamp with compound reflectors and a toric lens. Appl. Opt. 2015, 54, E102-E108. [CrossRef] [PubMed]

29. Chen, H.C.; Zhou, J.H.; Zhou, Y. Stacking illumination of a confocal reflector light emitting diode automobile headlamp with an asymmetric triangular prism. Appl. Opt. 2017, 56, 1087-1093. [CrossRef] [PubMed]

30. The Datasheet of OSRAM HWQP LED, OSRAM Opto Semiconductors GmbH. Available online: https: //dammedia.osram.info/media/resource/hires/osram-dam-5710564/LUW\%20HWQP_EN.pdf (accessed on 12 October 2019).

31. American National Standards Institute (ANSI). ANSI/NEMA FL 1-2009: Flashlight Basic Performance Standard; National Electrical Manufacturers Association: Virginia, VA, USA, 2009.

32. Sun, C.C.; Lee, T.X.; Ma, S.H.; Lee, Y.L.; Huang, S.M. Precise optical modeling for LED lighting verified by cross correlation in the midfield region. Opt. Lett. 2006, 31, 2193-2195. [CrossRef] [PubMed]

33. Chien, W.T.; Sun, C.C.; Moreno, I. Precise optical model of multi-chip white LEDs. Opt. Express 2007, 15, 7572-7577. [CrossRef] [PubMed]

34. Sun, C.C.; Chien, W.T.; Moreno, I.; Hsieh, C.C.; Lo, Y.C. Analysis of the far-field region of LEDs. Opt. Express 2009, 17, 13918-13927. [CrossRef] [PubMed]

35. Lewis, J.P. Fast Template Matching, Vision Interface 95. In Proceedings of the Canadian Image Processing and Pattern Recognition Society, Quebec City, QC, Canada, 15-19 May 1995; pp. 120-123.

36. Chen, J.J.; Lin, C.T. Freeform surface design for a light-emitting diode-based collimating lens. Opt. Eng. 2010, 49, 093001. [CrossRef]

37. Chen, J.J.; Wang, T.Y.; Huang, K.L.; Liu, T.S.; Tsai, M.D.; Lin, C.T. Freeform lens design for LED collimating illumination. Opt. Express 2012, 20, 10984-10995. [CrossRef] [PubMed]

38. Parkyn, W.A.; Pelka, D.G. New TIR lens applications for light-emitting diodes. Proc. SPIE 1997, 3139, $135-140$. [CrossRef]

39. Welford, W.T.; Winston, R. High Collection Nonimaging Optics; Elsevier Inc.: Amsterdam, The Netherlands, 1989; ISBN 978-0-12-742885-7.

40. Moreno, I.; Sun, C.C.; Ivanov, R. Far-field condition for light-emitting diode arrays. Appl. Opt. 2009, 48, 1190-1197. [CrossRef] 
41. Leccese, F.; Vandelanotte, V.; Salvadori, G.; Rocca, M. Blue light hazard and risk group classification of 8 W LED tubes, replacing fluorescent tubes, through optical radiation measurements. Sustainability 2015, 7, 13454-13468. [CrossRef]

42. Jung, M.H.; Yang, S.J.; Yuk, J.S.; Oh, S.Y.; Kim, C.J.; Lyu, J.; Choi, E.J. Evaluation of Blue Light Hazards in LED Lightings. J. Korean Ophthalmic Opt. Soc. 2015, 20, 293-300. [CrossRef] 